\title{
Microwave absorbing properties of structural nanocomposites with surface treated Co ferrite nanoparticles as filler (Withdrawal Notice)
}

\section{A. Jänis, R. Olsson, S. Savage, U. Klement}

A. Jänis, R. T. Olsson, S. J. Savage, U. Klement, "Microwave absorbing properties of structural nanocomposites with surface treated Co ferrite nanoparticles as filler (Withdrawal Notice)," Proc. SPIE 7644, Behavior and Mechanics of Multifunctional Materials and Composites 2010, 76441E (31 March 2010); doi: 10.1117/12.847556 Health Monitoring, 2010, San Diego, California, United States 


\section{Microwave absorbing properties of structural nanocomposites with surface treated Co ferrite nanoparticles as filler (Withdrawal Notice)}

Proc. SPIE 7644, 76441E (2010); http://dx.doi.org/10.1117/12.847556

Online Publication Date: 30 March 2010

Withdrawn from Publication: 30 June 2010

Conference Date: Monday 8 March 2010

Conference Location: San Diego, California, USA

Conference Title: Behavior and Mechanics of Multifunctional Materials and Composites 2010

Conference Chairs: Zoubeida Ounaies, Jiangyu Li

A. Jänis and S. J. Savage

Swedish Defence Research Agency (Sweden)

R. T. Olsson

Royal Institute of Technology (Sweden)

U. Klement

Chalmers Univ. of Technology (Sweden)

This paper was presented at the SPIE conference indicated above and has been withdrawn from publication at the request of the authors. 